\title{
Joule per Square Centimeter
}

National Cancer Institute

\section{Source}

National Cancer Institute. Joule per Square Centimeter. NCI Thesaurus. Code C67357.

A unit of radiant exposure equal to radiant energy of one joule arriving upon a surface area of one square centimeter. The unit is also used for measurement of output of the energy-emitting source. 